\title{
UNA RESPUESTA AL PROFESOR LEANDRO PRADOS DE LA ESCOSURA
}

\author{
JAMES SIMPSON * \\ Universidad de Alcalá de Henares
}

Es un placer para mí tener que responder a Leandro Prados de la Escosura. Su interés y los frecuentes comentarios críticos sobre mis trabajos de historia agrícola han sido siempre un estímulo para mí y por ello bien recibidos. Contestaré mejor sus últimas observaciones sobre mi artículo «La producción agraria y el consumo español en el siglo XIX» ', en el orden en que fueron presentadas.

1. La crítica de las fuentes. Prados apunta que caigo en el error de no llevar à cabo ninguna comprobación estadística que apoye las críticas que realizo a las estimaciones contemporáneas sobre la producción durante el siglo xix. Tiene razón. No obstante, sin investigaciones más profundas sobre precios, producción, mecanismos de mercado y elasticidades de demanda, es difícil determinar qué tipo de comprobación merecería ser llevada a cabo. Sin duda éste será un campo al que se le debería prestar una mayor atención en el futuro.

2. Prados argumenta, otra vez correctamente, que aun cuando el promedio de consumo de calorías per capita permaneciera constante durante el siglo, como sugiero, era posible que se hubiesen producido cambios en la composición de los productos, «con una mayor participación de productos con un valor unitario, esto es, de mayor calidad». En otras palabras, una dieta que he estimado en 2.100 calorías por persona y día podía, en un caso extremo, basarse en una dieta de caviar o, en el otro, en una dieta de pan de centeno. Sin embargo, como apunto en el artículo ${ }^{2}$, la información disponible sugiere que no se produce un crecimiento del consumo de los productos de alto valor durante el siglo. El consumo per capita de productos como el café, bacalao, azúcar y cacao seguía siendo limitado en 1900, y

* Agradezco a Juan Carmona Pidal sus comentarios.

1 Revista de Historia Económica, 1989, núm. 2, pp. 355-388.

${ }^{2}$ Pp. 376-378. 
el consumo de carne parece haber bajado durante el siglo. En contraste, parece que hubo un pequeño crecimiento del consumo de aceite de oliva y un crecimiento mucho más importante de patatas, probablemente a expensas de la carne. No obstante, en 1900 el coste por caloría de estos tres productos era notablemente similar, y cualquier sustitución entre ellos sólo pudo tener una importancia pequeña en el valor de la producción total ${ }^{3}$. Para la correcta realización de una investigación de este tipo y que abarcara todo el siglo, sería necesario disponer de los datos sobre los precios al consumo, una información que, de nuevo, aún no ha sido recogida.

3.1. Los intentos de Prados de la Escosura de reconciliar mi propia visión de una productividad agrícola en estancamiento con las cifras que ofrecen él y Carreras de una expansión de la producción industrial, son sugerentes, aunque quizá estén mal colocados.

Está claro que la economía española era considerablemente más avanzada en 1900 que en 1800. Esto se puede comprobar para todo tipo de factores: urbanización, incremento de la esperanza de vida, mayor producción de carbón y acero, reducción significativa de las repercusiones, crisis de subsistencia, etc... La lista podría ser sensiblemente alargada; sin embargo, convendría saber si esos "progresos» eran compatibles o no con una posible nula productividad en el sector agrícola. Aunque es evidente que ni Prados de la Escosura ni yo tendremos la última palabra en esta cuestión, creo que hay un número de puntos que necesitan ser recalcados.

El producto nacional y la productividad de los factores de producción son los instrumentos usuales para analizar la naturaleza del crecimiento de las sociedades industriales donde la producción es generalmente comprada y vendida a través de los mecanismos de mercado. No obstante, si producto nacional, no es de extrañar que éstos se multipliquen cuando se examinan las economías preindustriales ${ }^{4}$. En general mi artículo trataba de los problemas que plantea la estimación de las cantidades físicas producidas

3

\begin{tabular}{|c|c|c|c|}
\hline & $\begin{array}{l}\text { Calorias } \\
\text { por kilo }\end{array}$ & $\begin{array}{c}\text { Pesetas } \\
\text { kilo }\end{array}$ & $\begin{array}{c}\text { Pesetas } \\
1.000 \text { calorias }\end{array}$ \\
\hline 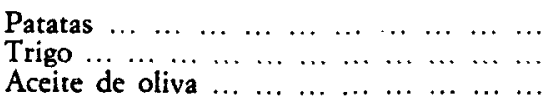 & $\begin{array}{r}700 \\
2.400 \\
8.800\end{array}$ & $\begin{array}{l}0,087 \\
0,255 \\
0,887\end{array}$ & $\begin{array}{l}0,124 \\
0,106 \\
0,101\end{array}$ \\
\hline
\end{tabular}

Fuente: Calculado por el Ministerio de Agricultura (s. a.), Sotilla (1911) y Simpson (1989). El precio del trigo no incluye el coste de su conversión en pan.

+ Por ejemplo, el tratamiento del trabajo doméstico no retribuido. 
y de paliarlos a partir del precio. Para estimar el producto agrícola es necesario conocer el precio que percibe el agricultor por su producto, o el que podía haber recibido en aquellos casos en que los productos no eran vendidos. Esto causa mayores dificultades y no sólo por las lagunas en los datos de precios de los productos agrícolas, especialmente para la primera mitad del siglo xIx, sino porque hay que suponer que existían mercados que les permitieran a los campesinos la posibilidad de vender la totalidad del producto ${ }^{5}$. Como he argumentado en la página 365 de mi artículo o como ha sugerido Ford para el vino en La Mancha, está claro que el sistema de mercado no siempre era capaz de disponer eficazmente del excedente en las economías con altos niveles de autosuficiencia ${ }^{6}$.

En segundo lugar, y en relación con lo dicho anteriormente, es seguro que, aunque tampoco sea posible medirlo, la proporción de producto agrícola vendida en el mercado creció notablemente a lo largo del siglo. Esto comporta implicaciones significativas para la contabilidad nacional. En un caso extremo es teóricamente posible una sociedad con una producción agrícola para el autoconsumo, de forma que como el transporte y la transformación del producto corre por cuenta del propio labrador, escapando por tanto a la estadística, el producto agrícola neto podría llegar a igualar la producción nacional ${ }^{7}$. Por contraste, si la misma sociedad, usando idénticos métodos agrícolas, decide y es capaz de vender toda su producción en el mercado y ésta es transformada por el sector «industrial», el resultado es que sin cambiar la productividad agrícola ${ }^{8}$, la contabilidad nacional registraría: a) la producción del sector de transporte, y b) la transformación de los productos agrícolas por la industria. ¡Por tanto, la economía crece!

Sin embargo, se produjo un incremento real de la productividad en la industria y el transporte en la España del siglo xIx, y como éstos estaban especialmente relacionados con la transformación y la venta de los productos agrícolas, los consumidores se beneficiaron de una oferta más amplia de bienes, de un suministro más seguro y de una mejora de la calidad de los productos. La importancia del proceso de elaboración de los alimentos industrialmente la ilustra el hecho de que suponía la mitad de las cuotas de la "Contribución industrial y de comercio» en 1856, y que se mantuvo en

${ }^{5}$ Los precios casi siempre proceden de capitales de provincia e incluyen, por tanto, el coste del transporte y los beneficios de los intermediarios.

- Ford (1906), p. 161.

' Los procesos de transformación más típicos consisten en la elaboración de la mantequilla y la fabricación del queso, la matanza doméstica, la preparación de las aceitunas, la producción de pasas, etc.

- El tiempo de ocio podía, sin embargo, crecer a medida que el labrador se fuera liberando de la necesidad de transformar su producción. 
torno a los dos quintos en una fecha tan reciente como $1900^{\circ}$. La importancia de la agricultura para el ferrocarril se puede medir por el hecho de que más de un 40 por 100 de los gastos de transporte de mercancías eran productos agrícolas entre 1875 y 1892 en las dos principales compañías del país ${ }^{10}$. Por lo tanto, aunque la productividad en la agricultura no hubiese crecido, el consumo urbano podía beneficiarse de los incrementos de la productividad obtenida en los sectores industriales y que indujeron una ampliación del mercado.

3.2. Prados de la Escosura sugiere que «son compatibles el aumento del producto por trabajador en el sector agrario y el mantenimiento de la importancia relativa de la agricultura como empleadora de la mano de obra». De nuevo esto puede aparecer teóricamente posible, pero el problema reside en comprobar si este fenómeno ocurrió realmente en la España del siglo xIX.

Un número de preguntas generales permanecen aún sin respuesta. ¿En qué dirección se movieron los precios agrícolas con respecto a los industriales? El lento crecimiento de la agricultura ¿fue un resultado de las limitaciones de la oferta o de un bajo crecimiento de la demanda? Estas y otras sugeridas en este debate sólo pueden ser contestadas recogiendo más material de archivo sobre precios y el funcionamiento de los mecanismos de mercado, junto con un uso apropiado de la teoría económica.

' Nadal (1987), Apéndice 2.1. Para los cambios en la naturaleza de la industria de transformación de alimentos, véanse las pp. $25-38$ del mismo artículo.

${ }^{10}$ En el caso de la del Norte, las cifras eran del 45 por 100, y para la MZA, 42 por 100. Calculado a partir de Tedde de Lorca (1978), cuadros IV.29 y IV-36 y los Apéndices IV.9 y IV-18. Los artículos incluidos en la del Norte eran aceites, trigos, harinas, vinos, vinagres, garbanzos y legumbres secas. Para la MZA, trigo, harinas, aceites, vinos, frutas, legumbres frescas, garbanzos y legumbres secas. 


\section{BIBLIOGRAFIA}

FORD, R. (ed.) (1906): Gatherings from Spain, Londres.

Ministerio de Agricultura, Industria, Comercio y Obras Públicas (s.a.): Noticias estadisticas sobre la producción agricola española por la Junta Consultiva Agronómica, 1902, Madrid.

Nadal, J. (1987): «La industria fabril española en 1900. Una aproximación», en NadAL, CARRERAS y SUDRIÀ: La economia española en el siglo XX: una perspectiva bistórica, Barcelona, pp. 23-61.

SimpSON, J. (1989): «La producción agraria y el consumo español en el siglo XIX», REvisTA dE Historia Económica, núm. 2, pp. 355-388.

Sotilla, E. de la (1911): «Producción y riqueza agrícola de España en el último decenio del siglo xix y primero del XX", Boletín de Agricultura Técnica y Económica, año V; reimpreso en Agricultura y Saciedad, núm. 8, 1981, pp. 331-409.

TEdde DE LoRCA, P. (1978): «Las compañías ferroviarias en España (1855-1935)», en M. Artola (dir.): Los ferrocarriles en España, 1844-1943, vol. 2, pp. 9-354. 